\title{
Autópsias psicológicas sobre suicídio de idosos no Rio de Janeiro
}

\author{
Psychogical autopsies into suicide among the elderly \\ in Rio de Janeiro
}

Maria Cecília de Souza Minayo ${ }^{1}$

Fátima Gonçalves Cavalcante ${ }^{2}$

Raimunda Matilde do Nascimento Mangas ${ }^{1}$

Juliana Rangel Alves de Souza ${ }^{2}$

${ }^{1}$ Centro Latino Americano de Estudos de Violência e Saúde Jorge Carelli, Escola Nacional de Saúde Pública, Fiocruz. Av. Brasil 4036/ 700, Manguinhos.

21040-361 Rio de Janeiro RJ. cecilia@claves.fiocruz.br ${ }^{2}$ Laboratório de Práticas Sociais Integradas, Mestrado Profissional em Psicanálise, Saúde e Sociedade, Programa de Iniciação Científica, Universidade Veiga de Almeida.

\begin{abstract}
This study analyses psychological autopsies and contextualizes problems and issues that led to elderly people taking their own lives in the city of Rio de Janeiro between 2004 and 2007. The study began with an analysis of 26 expert findings of elderly men and women who committed suicide in the central, northern and southern areas of Rio de Janeiro. The sample was contacted by letter and telephone and after that, by a oneon-one conversation. Eight psychological autopsies were conducted, in which identification data and family genograms were collected followed by an interview to profile the life style and the reasons for the self-inflicted violence. The interviewees were family members, friends and acquaintances of the victims. The suicides are associated with depression, serious physical and mental illness, as well as socio-cultural factors related to professional and socio-economic decline. The suicides occurred with and without family support, with and without medical care. The cumulative fragility of personal and social resources within the life cycle reveals that the risk of suicide among the elderly demands permanent care from the public health authorities.
\end{abstract}

Key words Suicide, Suicide among the elderly, Psychological autopsies
Resumo Esse estudo analisa autópsias psicológicas e contextualiza problemas e fatores que levaram algumas pessoas idosas a acabar com a própria vida na cidade do Rio de Janeiro, entre 2004 e 2007. O estudo parte de 26 laudos periciais de homens e mulheres que cometeram suicídios no centro, na zona norte e na zona sul da cidade. As famílias desses idosos foram contatadas por carta e telefone e depois, pessoalmente. Foram oito autópsias psicológicas, por meio das quais foram coletados dados de identificação, genograma da família e uma entrevista que reconstituiu o modo de vida e as razóes da violência autoinfligida. Os entrevistados foram familiares, amigos e conhecidos das vítimas. Os suicídios estão associados a depressão, a enfermidades físicas e mentais graves e a fatores socioculturais como decadência profissional e socioeconômica. Esses eventos ocorreram com e sem apoio familiar, com e sem acompanhamento médico. A fragilização cumulativa de recursos pessoais e sociais no ciclo vital revela que o risco do suicídio em idosos exige cuidados permanentes de saúde pública.

Palavras-chave Suicídio, Suicídio em idosos, Autópsias psicológicas 


\section{Introdução}

Apresentam-se os resultados de uma pesquisa baseada em autópsias psicológicas relativas a suicídios cometidos por pessoas de 60 a 80 anos ou mais, entre os anos de 2004 e 2007 na cidade do Rio de Janeiro. Este estudo teve o apoio da Fundação de Amparo à Pesquisa do Estado do Rio de Janeiro (Faperj). Embora focalize uma realidade local, ele tem importância acadêmica e social, pois muito pouco se encontra sobre o tema suicídio em idosos na literatura nacional. Contextualizam-se, também, os conhecimentos gerados no trabalho de campo com as referências internacionais encontradas na última década.

A autópsia psicológica ${ }^{1-4}$ é uma abordagem retrospectiva que permite esclarecer as situações em que ocorreu a morte, a partir de fatos relevantes na vida do suicida e de seu contexto sociocultural e relacional e das possíveis causas de seu ato. As autópsias psicológicas, tais como propostas por Shneidman ${ }^{1,2}$, baseiam-se nas teorias da suicidologia que analisam os diferentes graus de perturbação que levam uma pessoa a dar cabo à própria vida ${ }^{5,6}$. Para Shneidman ${ }^{6}$, e Baechler ${ }^{7}, \mathrm{o}$ suicídio é um ato consciente de autoaniquilamento, compreendido como um mal-estar multidimensional sofrido por um indivíduo vulnerável, que define um tema-problema para o qual o autoextermínio é percebido como melhor solução.

Relacionado à interação de fatores, pode-se dizer que o suicído constitui uma espécie de: (a) escape de intenso sofrimento quando se associam necessidades frustradas com nível de estresse insuportável, (b) estreitamento de opções associado a sentimentos de desesperança, desamparo e desejo irresistível de fuga por parte do sujeito ${ }^{6,7}$. Entre os fatores de risco mais conhecidos estão: rompimentos emocionais, perdas reais ou imaginárias, transtornos depressivos, enfermidades graves, problemas mentais, falta de perspectiva de futuro, desemprego, aposentadorias sem alternativa de aproveitar a vida, queda no padrão vida e estresse cumulativo ${ }^{8,9}$. Os sinais para risco do suicídio podem ser identificados através de pistas verbais, comportamentais, contextuais e situacionais $^{8-10}$.

Segundo a Organização Mundial de Saúde ${ }^{9}$ 840 mil pessoas se suicidaram no ano de 2004 . As taxas de suicídio variam entre países e a maior parte dos estudos revela que existem diferenças por faixa etária, sexo, raça e etnia ${ }^{11-13}$. No Brasil, as taxas realtivas a esse fenômeno são consideradas baixas ${ }^{8,9}$ e oscilaram entre 4,5/100.000 em 2000 e 5,7/100.000 em 2007. Na população idosa, elas variam entre 6,8/100.000 em 2000 e 8,0/100.000 em 2007, revelando aumento significativo entre idosos do sexo masculino ${ }^{13}$. Um estudo realizado em 2007 em 62 países mostra que as taxas de suicídio aumentam com a idade, para homens e mulheres ${ }^{14}$.

A tensão entre causas sociais, microssociais, psicológicas, médicas e ambientais ${ }^{13-20}$ na caracterização dos suicídios acompanha toda a análise que será aqui apresentada.

\section{Material e Método}

O estudo partiu de laudos periciais que permitiram a identificação de endereços e contatos telefônicos de parentes e amigos das vítimas, alguns dos quais, uma vez contatados, concederam entrevistas para as autópsias psicológicas cujo roteiro será comentado a seguir.

Acesso aos laudos periciais - Inicialmente foi realizado um levantamento de casos ocorridos no município do Rio de Janeiro entre 2004 e 2007, registrados pelo Instituto de Criminalística Carlos Ebóli (ICCE-RJ) ${ }^{21}$. O ICCE desenvolve perícias locais sobre homicídio, suicídio, acidentes de trânsito e arrombamentos, entre outras atividades. As informações referiram-se ao sexo, idade, formas de perpetração do suicídio, local de ocorrência e nomes de informantes incluídos nos laudos (parentes e pessoas próximas) de suicidas idosos que viviam no centro, na zona norte e na zona sul, área de abrangência do ICCE.

No período, a perícia técnica registrou 117 suicídios para todas as idades em sua área de abrangência. No entanto apenas 60 laudos foram localizados. A dificuldade desse primeiro levantamento se deveu, sobretudo, ao fato dos arquivos ainda não serem digitalizados, exigindo-se busca manual dos documentos. Dos 60 laudos encontrados, 26 eram de pessoas acima de 60 anos ( 10 mulheres e 16 homens). Desse total, dezessete mortes ocorreram por precipitação voluntária e queda de altura (oito homens e nove mulheres); duas por enforcamentos (homem e mulher); cinco por arma de fogo (quatro homens e uma mulher), uma por envenenamento (homem), e uma cuja forma de perpetração não foi esclarecida. Do total, duas mortes não foram incluídas pelos peritos como suicídio, pela dúvida quanto à causa primária ${ }^{21}$.

Geograficamente, quinze suicídios ocorreram na Zona Sul, conhecida por seus bairros de classe média, praias e população com elevado poder aquisitivo. Nove aconteceram no Centro e duas 
na Zona Norte, em áreas com estratos populacionais de médio e baixo poder aquisitivo. Das 26 pessoas, $23,1 \%$ tinham de 60 anos; $15,4 \%$ de 61 a 65 anos; $19,2 \%$ de 65 a 70 anos; 19,2\% de 71 a 75 anos; $11,5 \%$ de 76 a 80 anos; $7,7 \%$ de 81 a 85 ; e $3,8 \%$ acima de 85 anos $^{21}$.

Seis das entrevistas foram realizadas na Zona Sul e duas na Zona Norte. Embora tenha sido um grupo pequeno, a pesquisa permitiu ouvir histórias de suicidas (homens e mulheres) de classe média, de classe média alta, de baixa renda e de diferentes estratos de idade entre os idosos.

Dados para as entrevistas- Alguns laudos traziam nomes de parentes, amigos ou de síndicos que acompanharam o trabalho dos peritos e a liberação dos corpos. Essa informação foi crucial para se localizar os possíveis interlocutores por endereços e posteriormente, por telefone. Concomitantemente, a equipe elaborou duas cartas solicitando aos possíveis entrevistados que participassem da pesquisa. Nelas também se orientava sobre a importância do estudo. Ambas tinham semelhante teor: uma era endereçada aos síndicos dos edifícios em que os suicídios ocorreram e a outra, aos parentes. Foram enviadas 48 cartas para 24 endereços. Obteve-se retorno de apenas quatro. O procedimento mais exitoso foi o contato telefônico. Para 12 casos não se conseguiu localizar parentes ou conhecidos. Houve três recusas: num caso, parentes ou pessoas próximas se sentiram indignadas por alguém se atrever a perguntar sobre o assunto; noutro, o interlocutor disse simplesmente que não gostaria de falar desse tema; e outro ainda, considerou o assunto encerrado para a família.

Uma característica do suicídio enquanto fenômeno social se tornou evidente: trata-se de um tema tabu que mobiliza uma ferida emocional grande sobre a qual poucos aceitaram falar. Esses tinham as seguintes relações com os que morreram: três filhas, um filho, uma irmã, um amigo, duas síndicas e um neto, a maioria na faixa de 40 a 55 anos. $\mathrm{O}$ amigo e as síndicas conheciam as vítimas há muitos anos. Os demais eram parentes de primeira ou segunda geração.

Os aceites para participação ocorreram por razões diferentes. Alguns entenderam a entrevista como oportunidade de troca e partilha sobre um assunto difícil de falar, de pensar e de esquecer. Outros a viram como um raro momento para alivio do sentimento de culpa. Para um dos interlocutores, as pessoas sentem medo de falar ou pensar sobre isso porque elas tendem a se perguntar se teriam podido fazer algo mais para evitar o ocorrido. Outros participaram por preocupação com a solidão e o isolamento em que muitos idosos vivem. Alguns se mostraram muito fragilizados e tiveram apoio pontual das entrevistadoras que eram duas psicólogas.

É importante lembrar que embora houvesse um desejo das pesquisadoras de constituir uma amosta qualitativa significativa, as autópsias psicológicas foram realizadas com quem se dispôs a colaborar. Aqui como em qualquer país do mundo, a dificuldade de chegar a familiares de suicidas é muito grande ${ }^{6}$ Além disso, trabalha-se com relatos que reconstituem uma memória afetiva e social muito próxima para quem testemunhou o ocorrido. Nesse sentido, investiga-se com o que Evans-Pritchard ${ }^{22}$ chamou de tempo estrutural em que não se pode esperar precisão de datas e exatidão de detalhes, pois o que manda são os processos emocionais e a memória de fatos relevantes para o sujeito. É impressionante como acontecimentos que geram profunda dor e sofrimento imprimem em familiares e amigos memórias tão difíceis de esquecer. Nesse sentido, foram tomados os cuidados apontados pela literatura ${ }^{3}$, que recomenda o estudo de casos entre dois e cinco anos de falecimento, período que já se prevêem diferentes graus de elaboração do ocorrido, situar com menor carga emocional a circusntância da morte e avaliar o impacto da mesma nos familiares e pessoas próximas.

Procedimentos - As entrevistas tiveram até duas horas de duração. Todos os participantes assinaram o Termo de Consentimento e autorizaram a gravação da conversa. Os encontros foram realizados no Centro de Saúde de uma universidade ou no local de trabalho dos entrevistados. Todos os espaços para a entrevista foram acolhedores e silenciosos, exceto num caso, em que o entrevistado optou por conversar em um restaurante também bastante discreto e adequado.

A entrevista foi feita em três momentos: (1) preenchimento de uma ficha de identificação pessoal da pessoa que cometeu suicídio; (2) elaboração de um genograma da família visando: compreender o lugar afetivo do suicida e o perfil socioeconômico dos familiares de três gerações; conhecer a rede de relações, de alianças e de conflitos familiares; e apontar os acontecimentos críticos do ciclo vital da família; (3) realização da entrevista propriamente dita ${ }^{3}$ com uma abordagem sociocultural e familiar da pessoa que cometeu o suicídio, uma caracterização social (escolaridade, experiência profissional, rendimento, moradia), e o modo de vida, situando problemas familiares ou socioeconômicos e contatos significativos. Nesse momento se avaliou de 
forma aprofundada, o contexto do ato suicida, os fatores que o desencadearam, os apoios sociais que a pessoa possuía e o meio empregado. Dentro do possível, analisou-se com o interlocutor o estado mental que antecedeu a morte, a imagem do suicida na família, o momento do sepultamento, o impacto do autoextermínio na rede familiar e os problemas que a família enfrenta atualmente, por causa do evento.

O processo de análise foi respaldado em revisões bibliográficas e estudos sobre idosos ${ }^{16,20,23,24}$. Os casos foram contextualizados, descreveramse o perfil dos suicidas e os motivos atribuídos pelos interlocutores para os atos fatais praticados. A seguir foi realizada uma análise em que se combinaram categorias teoricamente respaldadas com categorias empíricas trazidas pelo interlocutor. E por fim, foram discutidos os fatores de risco associados ao suicídio em idosos e realizada uma breve reflexão sobre o impacto desse fato na família.

O projeto de pesquisa foi aprovado pelo Comitê de Ética da Fundação Oswaldo Cruz.

\section{Resultados}

Segundo o IBGE ${ }^{25}$, o Rio de Janeiro é a metrópole brasileira com a maior concentração de idosos no Brasil e o bairro de Copacabana é aquele que concentra o maior número absoluto, sendo que quase $1 / 3$ de sua população tem mais de 60 anos. Por essa razão, embora esta pesquisa se restrinja a três regiões geográficas da cidade do Rio de Janeiro, ela analisa uma área de elevado adensamento de idosos no estado e no país. A partir do levantamento dos dados do Instituto Carlos Éboli foi possível observar dois pontos relevantes: maior prevalência de suicídios de pessoas de classe média; e o principal meio empregado pela maioria dos suicidas: precipitação por queda livre $(65,4 \%)$ do alto dos edifícios. Essa constatação contraria a tendência nacional ${ }^{13,14}$ e do próprio Estado do Rio de Janeiro quanto à forma de cometimento de suicídio, cuja via mais comum é o enforcamento. No caso desse Estado, entre 2004 e 2007 o meio mais utilizado foi o enforcamento (110 dos 239 casos registrados) por pessoas de todas as idades; vindo a seguir os autoextermínios por arma de fogo (49 casos); por queda de altura (44); por meios não esclarecidos (26); e por envenenamentos com produtos químicos $(10)^{24}$. Para o Brasil, os meios principais usados pelos que cometem suicídio são os enforcamento, armas de fogo e envenenamento ${ }^{13,24}$
Contextualização dos casos - Embora o sucídio entre homens idosos seja de maior prevalência do que entre mulheres idosas no Brasil e na maioria dos países, no trabalho de campo teve-se acesso a mais familiares de mulheres suicidas do que de homens, uma vez que trata-se de um estudo feito por adesão voluntária de entrevistados. Além de se agrupar os casos por sexo e faixa etária, a análise a seguir aponta entre os fatores causais, aspectos subjetivos, intra ou interpessoais, transpessoais, socioculturais e socioeconômicos.

Perfil dos casos - Foram analisados oito suicídios consumados. Foram dois suicídios por enforcamento: de um homem e uma mulher; cinco por queda de altura, todos cometidos por mulheres que moravam no sexto, sétimo, oitavo e décimo primeiro andar de seus edifícios; e um de um homem por envenenamento. Cinco das mortes ocorreram ao amanhecer e três ao entardecer, muitas após uma noite de sono conturbada e três após um último contato com o cuidador ou um parente.

Há uma representação de dois suicidas masculinos na faixa de 60 anos; de duas mulheres de 63 e 64, de duas de 71 e 72 e de duas com 80 anos. Os eventos analisados ocorreram entre os anos 2004 e 2007.

Motivos atribuidos - Nos dois casos de suicídio cometidos por homens, o primeiro foi relatado por um amigo de infância, tão próximo do que morreu por envenenamento que pareceu estar recompondo a perspectiva da própria vítima. Tratava-se de, um profissional liberal na faixa de 60 anos, que viveu uma decadência pessoal e econômica aliada a progressivo rompimento familiar. Isso o deixou numa solidão que o corroeu tanto quanto o veneno que lhe tirou a vida, conforme o amigo. O segundo é de um imigrante de língua castelhana, cuja história foi narrada pela filha. Esse homem se enraizara no país, constituindo família e carreira profissional. Mas perdeu quase todos os bens materiais e vivia descontente, passando de dono a empregado, numa vida de "subemprego" que ruiu sonhos e afetou sua visão de masculinidade como provedor da casa. Segundo a filha ele repetia: um homem que não é mais homem não precisa mais viver. Ele mesmo sentenciou sua morte por enforcamento. Ambos os casos apresentam homens infelizes com o destino social e econômico ${ }^{18}$ e, em função disso, desenvolveram um quadro depressivo.

Os seis casos de suicídio de mulheres se caracterizam por ocorrer nos anos iniciais de cada faixa etária. Os dois primeiros na faixa dos sessenta anos. Esses retratam a experiência de pes- 
soas que haviam sido bem sucedidas em suas respectivas profissões, a primeira como educadora e a segunda, como profissional de saúde. A história da educadora foi relatada pela filha que a acompanhara com cuidado e zelo. Essa mulher que viveu dois casamentos e foi provedora da família por muitos anos, valorizando o trabalho e a estabilidade, foi afetada duramente por uma aposentadoria mal planejada. Seu mal estar culminou com o jogar-se do sexto andar do edifício em que morava. O caso da profissional de saúde foi contado por uma irmã mais nova, ambas com traços de transtorno bipolar, morbidade que afetou outros integrantes da família na primeira e segunda geração. Graças a recursos médicos e psicoterápicos, essa profissional conseguiu manter-se compensada na maior parte de sua vida, o que lhe assegurou a carreira e a profissão numa instituição pública, até que um câncer grave e terminal lhe trouxe uma desorganização psiquiátrica e exigiu internação. De retorno a casa, cometeu o ato fatal: jogou-se do $11^{\circ}$ andar de seu edifício. Esses dois casos ocorreram em horários em que os cuidadores dormiam: o primeiro ao amanhecer e o segundo, à noite.

$\mathrm{Na}$ faixa inicial dos setenta anos, há os casos de duas mulheres duramente marcadas por situações de perda de parentes próximos. A primeira história foi contada por um filho único, altamente impactado pelo episódio. Após mais de cinquenta anos de vida conjugal, o marido passou por uma internação hospitalar de seis meses e veio a falecer. Sua mãe, frente a tais circunstâncias se deprimiu de forma grave que não conseguiu superar o sofrimento pela hospitalização e morte do companheiro de toda a vida.

O segundo caso foi narrado pela síndica do prédio, na ausência de referência familiar, uma vez que a mãe e a irmã que moravam com a idosa tinham falecido havia menos de dois anos, deixando-a sozinha. Essa mulher sofria de transtorno mental, fumava compulsivamente e era viciada em jogo de bingo, comorbidade que traz uma combinação bombástica entre sintomas psiquiátricos e traços compulsivos ${ }^{19}$. Ela era muito agressiva e tinha dificuldade de relacionamento com as duas parentas quando eram vivas. Por ocasião do suicídio, seu estado de higiene era precário e se encontrava em surto psicótico agudo, com alucinações sinestésicas. Apesar de possuir muitos recursos financeiros, essa idosa não se deixava ajudar, a ponto de se aparentar como mendiga pela precariedade dos cuidados dispensados a si e ao ambiente em que morava. Essas duas mulheres, ao amanhecer se jogaram, respectivamente, do oitavo e do décimo primeiro andar de seus apartamentos. Enquanto a primeira não exibia sinais de depressão, a segunda parecia estar no fundo do poço. Nesses dois casos, não havia presença de cuidadores nas residências.

$\mathrm{Na}$ faixa inicial dos oitenta anos, relatam-se os casos de duas mulheres que haviam dedicado suas vidas à profissão e à família. Uma das mortes foi marcada pela presença de depressão grave e crônica e a segunda, pela ausência de qualquer tipo de transtorno físico ou mental. A história da primeira foi contada pela filha que acompanhou o tratamento da mãe, oferecendo-lhe todos os recursos e terapêuticas disponíveis. Sua genitora havia sido educadora e escritora, autora de dezenas de livros e ficara viúva há mais de três décadas. Seus filhos estavam formados. Mas ela sentiu dificuldades de aceitar o envelhecimento e as perdas dos entes queridos. Sua depressão se agravou após a morte repentina do irmão caçula. Ela havia atravessado uma década de tentativas de tratamentos nem sempre exitosos, por causa dos efeitos paradoxais dos medicamentos. O desfecho culminou com o médico desistindo de atendê-la por sua falta de adesão às prescrições. A família ainda tentou outro profissional que lhe ofereceu uma prescrição medicamentosa, avisando à família que seu uso incluía risco de suicídio. Mesmo com todos os cuidados com que os familiares a cercaram, essa idosa se jogou do sétimo andar, ao amanhecer, enquanto sua acompanhante dormia.

O segundo caso foi contado pelo neto que acompanhou as circunstâncias de vida e de morte da avó. Essa senhora tinha três filhas, quatro netos e três bisnetos, e era dedicada ao lar e à família: pessoa ativa, sem transtorno físico ou psíquico. Vivia envolvida com problemas de saúde de familiares e de gerenciamento financeiro da família extensa que invadia seu espaço pessoal e usava seu dinheiro sob pretexto de ajudá-la. Duas semanas após uma discussão em família e o desaparecimento de um dos seus cartões bancários, essa idosa enforcou-se ao entardecer. Apenas através de sua morte, ela conseguiu impor limites e produzir um processo de diferenciação nas relações familiares marcadas pela dependência, concluiu o neto.

\section{Discussão}

Fatores de risco e associados ao ato suicida - Nos casos dos dois homens já relatados, embora tenha havido um tom depressivo em ambas as his- 
tórias, a perda de sentido da vida associada a fatores sociais parece ter sido determinante para a decadência pessoal, social e econômica que fragilizou a vida de ambos, nos termos a que se refere Durkheim ${ }^{18}$.

Para o profissional liberal, o ponto de partida da decadência social e econômica foi o Plano Collor, que confiscou a poupança com que tentava garantir a vida familiar e seu futuro. Desde então sua carreira regrediu, os laços familiares se fragilizaram e se romperam. Ao longo de anos, ele desenvolveu a síndrome de dependência do álcool. No último mês de vida, numa mesa de bar, verbalizou um pedido de ajuda: não me deixe sozinho. O curto bilhete deixado foi eloquente: $O$ infarto é iminente e a solidão corrói. Já o imigrante europeu não se conformava de passar de empregador a empregado e de se submeter a outros. Segundo a filha, ao final, perdera a alegria de viver: terminou seus dias trabalhando como porteiro do prédio em que morava, o que considerava uma humilhação. Esse senhor também deixou uma mensagem: Qualquer dia eu vou me matar; qualquer dia eu apareço morto. O que eu estou fazendo aqui? Falharam-lhe os sonhos de ascensão social na terra que escolheu para recomeçar a vida.

Das mulheres, duas acumulavam histórias de superação de graves problemas durante a vida, por isso, deixaram perplexas suas famílias. Uma era educadora e já havia passado por episódios depressivos, tendo elaborado perdas pela morte de familiares e enfrentado o drama da recuperação de uma filha após um grave acidente de trânsito. Havia vivido dois casamentos mantendo a família unida e uma carreira profissional ativa. Mas emocionalmente não aceitou a aposentadoria. Comentou com sua filha: A sensação dela é que a gente estava na falência, que o dinheiro estava acabando. Nos últimos momentos eclodiulhe um grave quadro depressivo como mostra o diálogo mãe-filha: -Ah eu queria sumir. Sumir da vida das pessoas, sumir, sumir. A filha tentava dissuadi-la, mas ela insistia: Eu quero morrer! É muito sofrimento!

A mulher que trabalhou na área de saúde e atravessara sua vida superando um transtorno mental bipolar que mantinha sob controle graças a cuidados terapêuticos, um câncer lhe tomou os dois seios e se enraizou em seu corpo desmoronando sua delicada estrutura psicológica. Nessas duas histórias, a depressão aparece associada ao suicídio: para a educadora, a depressão grave foi desencadeada por uma aposentadoria mal planejada e pelo efeito cumulativo de fatores estres- sores ao longo da vida. Para a profissional de saúde, a depressão se associou ao câncer terminal, à eclosão de crises e à humilhação de internações psiquiátricas. Como diz Shneidman ${ }^{6}$, a queda de altura foi uma solução encontrada para um mal estar multidimensional. Simbolicamente, uma morreu quando perdeu a identidade como professora e a outra quando, de profissional de saúde passou a paciente grave. Os dois casos revelam o quanto fatores subjetivos, médicos e sociais estão imbricados, marcando o lugar do indivíduo na comunidade e na cultura.

Das duas mulheres na casa dos 70 anos, ambas foram duramente golpeadas com as mortes de parentes próximos e a perda das principais referências familiares. A viúva viveu a morte de um marido trabalhador e dedicado à família. Segundo o filho, o pai era muito carinhoso e acompanhava a mãe em tudo: Eles eram muito grudados! Sem sinais visíveis de quadro depressivo, poucos meses depois da morte do companheiro, ela se atirou do apartamento onde morava. Já a mulher com transtorno mental teve seu quadro agravado após perder mãe e irmã, também idosas: Segundo a síndica: ela desconfiava de tudo e de todos e tinha muitas manias. Quando se atirou do apartamento em que morava, apresentava forte desorganização psicótica. As perdas mal elaboradas acirraram sua fragilização agravando um transtorno psiquiátrico severo. Nesses dois casos, o fator desencadeante foi a depressão associada a fatores microssociais.

Por fim, comentam-se os casos das duas mulheres que deram cabo a sua vida após os 80 anos. Em suas histórias existe em comum a faixa etária de maior risco para suicídio, que segundo estudos internacionais e nacionais está acima dos 75 anos $^{6,8-12,20}$. Para a escritora que tivera uma carreira brilhante, o envelhecer foi se tornando difícil, na medida em que suas habilidades se esvaiam: Já não estou mais escrevendo, já não tenho mais ideias, minha cabeça já não está muito boa. Essa perda de identidade associada a uma grande tristeza pelas mortes de entes queridos lhe fez eclodir um quadro depressivo que foi se tornando crônico e de difícil tratamento ao longo de uma década. Comentou a filha: Nos anos seguintes ela não conseguia sair daquela tristeza dizendo sempre 'eu não aguento mais'. Ela reclamava muito que não estava se reconhecendo, que não queria viver, e que preferia morrer.

Já a outra octogenária fora sempre dona de casa e dedicada à família. Depois que envelheceu e se enviuvou, a administração financeira de seus bens era feita de forma abusiva por parentes - e 
isso parece ter sido um dos fatores desencadeantes para seu suicídio - situação associada a uma demanda excessiva de suas energias para solucionar problemas familiares. Ela que sempre ordenara os assuntos domésticos, aos poucos via tudo fugindo a seu controle e a sua possibilidade de solucionar os problemas. Segundo o neto, sua avó dizia: Quando eu morrer, eu não vou dar trabalho a ninguém, a pessoa já vai me encontrar morta.

A escritora atirou-se do apartamento em que morava, à revelia de uma cuidadora. E a dona de casa enforcou-se na própria casa, para a perplexidade das filhas, netos e genros. No primeiro caso a depressão profunda foi um fator crucial associado à tristeza pelo envelhecer e pela perda de habilidades. No segundo, a carga que significavam os problemas familiares e financeiros que os filhos, genros e netos não souberam retirar das costas de uma pessoa com mais de 80 anos foram determinantes.

Impacto do suicídio nas famílias - Em geral, a literatura sobre o suicídio aponta o forte impacto do suicídio no ambiente familiar ${ }^{4-6,9,10}$. Em todos os casos estudados isso ocorreu. O suicídio do pai de família que não se conformou com a perda dos bens e do status deixou um vazio e uma interrogação em sua filha. Ela comenta: Ele tinha uma família bonita, que já estava se multiplicando, não tinha problema financeiro, não tinha vício, não bebia e nem fumava, era uma pessoa super correta. Como ele teve coragem para fazer o que fez? A família sentiu revolta e tomou-se de uma tristeza muito grande, o que continua a influenciar a vida da filha, anos depois: Eu sofri muito, é difícil pôr em palavras. Eu fui me conformando porque não tinha outra solução. O tempo traz um conforto, uma aceitação que não é total. Eu fiquei meio fria e meio arredia, a ponto do meu marido até hoje perceber.

Os efeitos do ato suicida também afetam a vida de amigos: Eu podia esperar tudo dele, tudo. Até que ele, desesperado, praticasse um ato ilícito. Mas não essa atitude de se matar. Eu nunca acreditei nessa possibilidade, pela personalidade dele, pelo humor dele, pela religião que ele professava e seguia. O amigo, quase irmão, percebeu em si traços profundos de amargura, a partir desse evento: as pessoas, às vezes olham para mim e acham que eu sou frio. Não, não sou. É que estou diante de um fato sem solução. Tenho vontade de passar uma borracha e apagar tanta dor.

Uma filha contou com grande tristeza que alguns amigos nunca mais falaram com ela após a morte da mãe. E que, também, têm sido necessários muitos anos para a família digerir essa histó- ria que tende a causar muita briga, são uns culpando os outros pelo acontecido. Mas segundo essa mulher, o tempo vai trazendo outros discernimentos sobre o que ocorreu e maior clareza de que as pessoas, por vezes, decidem pelo fim de suas vidas, independentemente dos cuidados que recebem.

Ainda outra filha partilha sua visão acerca do suicídio da mãe: a forma como aconteceu foi muito contraditória para mim. Destrói e me destrói. Ela não merecia ter esse final. Não tem a ver com a história dela, não tem a ver com a vida dela. Apenas dois anos se passaram e ela comenta que se sente despedaçada emocionalmente, mas em fase de reconstrução: $O$ impacto em mim é estarrecedor: você acorda e tem aquela sensação de que nunca vai deixar de sentir esse vazio. É preciso aprender a viver com essa dor, com essa parte da história. É um aprendizado, pois isso não passa. Mas você reaprende a olhar para o céu, a olhar para o mar, a olhar para o sol.

Uma característica comum em todos os casos é a amargura e a tristeza permanente dos familiares, seja por culpa, seja por saudade, seja pela vivência muito forte de ter um familiar que se matou. Um efeito de ruptura em cascata, como se viu em alguns casos, pode reverberar em muitas famílias, parentes e amigos diante das consequências em longo prazo de um suicídio. Justo no momento em que todos precisariam se aproximar, se unir, se consolar, há inúmeras desavenças. Esse aspecto precisa ser levado em conta pelos profissionais de saúde ao cuidar de pessoas com história de suicídio na família.

\section{Considerações finais}

Este estudo começou com laudos periciais e terminou com a reconstituição da história de algumas pessoas que cometeram suicídio. Os suicídios aqui analisados estão associados à depressão, às enfermidades físicas e mentais graves e aos tratamentos médicos, aos fatores socioculturais como decadência profissional e socioeconômica, à aposentadoria mal planejada, aos abusos financeiros por parte da família, o que corrobora com os estudos internacionais ${ }^{6,19,20}$. Entre os temas sociais, destaca-se o impacto de crises econômicas na vida dos indivíduos. Do ponto de vista existencial, a dificuldade de aceitar o envelhecimento e seus limites ${ }^{4,6,10}$. Um dos casos está associado à questão de impregnação e intoxicação por medicamentos para transtornos mentais, um problema objeto hoje de preocupações para o setor saúde ${ }^{26}$. E, por parte da família, 
ressalta-se o peso sobre os idosos dos abusos financeiros e a sobrecarga sobre alguém que, ao contrário, precisaria ser cuidado ${ }^{6,20}$.

Constata-se também que famílias, parentes e amigos muitas vezes não levam a sério as intenções de suicídio explicitadas pelos idosos. No entanto, uma ideação nessa faixa etária pode ser mais rapidamente colocada em prática como a literatura revela ${ }^{15,24}$. Estudo realizado pelo WHO/ Euro Multicentre Study of Suicidal Behaviour ${ }^{27}$ mostra que a relação entre tentativas e suicídios consumados, na população idosa, em 13 países da Europa é de 2:1.

O impacto do suicídio na família não se limita a sofrimentos individuais. Ele inclui o sistema familiar e a rede de amigos, produzindo rupturas nos laços afetivos e sociais, o que pode provocar o isolamento de pessoas, parentes e amigos, limitando ou cerceando trocas que seriam fundamentais para o reequilíbrio desse grupo. A amargura que afeta parentes e amigos deve ser vista cuidadosamente pela área da saúde, pois o "desastre afetivo-social" precisa ser acompanhado com instrumentos adequados para cuidar daqueles que sobreviveram e que terão que conviver com a história do suicídio.

A fragilização cumulativa de recursos pessoais e sociais no ciclo vital mostra que o risco de suicídio em idosos exige cuidados permanentes da área de saúde pública. Em diversos países ${ }^{8-}$ 11,15,27, ações de promoção de saúde, pronto atendimento frente a situações de risco, acompanhamento de doenças físicas e transtornos mentais, implementação de programas nacionais de saúde mental e de prevenção do suicídio têm favorecido a redução desse problema.

Hoje a OMS disponibiliza um importante manual chamado SUPREMISS (Estudo de Intervenção sobre Comportamento Suicida em Múltiplos Locais ${ }^{28}$ que orienta os profissionais de saúde desde a atenção primária até os níveis mais complexos de intervenção. Seu pressuposto é de que é possível prevenir a morte autoinfligida em qualquer idade. Também o Ministério da Saúde, por meio de uma parceria com a Organização PanAmericana de Saúde (OPAS) e a Universidade de Campinas (Unicamp) elaborou um Manual de Prevenção do Suicídio dirigido a profissionais das equipes de saúde mental ${ }^{29}$. Mas a questão do suicídio, sobretudo na população idosa ainda tem merecido pouca atenção da sociedade e do setor saúde, particularmente no Brasil. É preciso que esse tema não seja alvo de sensacionalismo e sim tratado de forma compreensiva e multidisciplinar.

Ressaltando a necessidade de se adotar uma visão complexa do problema, encerra-se este trabalho com a importante advertência de Beeston ${ }^{20}$ : um sentido de conectividade social e de participação na vida comunitária parece ser protetiva contra o suicídio em pessoas idosas. Portanto, o desenvolvimento de uma rede social de suporte para essas pessoas deveria ser definido como prioridade. Mas devemos alertar que a rede de relações pessoais e de amizade das pessoas idosas vem sendo cada vez mais substituída por serviços profissionais pagos. Isso pode ser problemático para eles.

\section{Colaboradores}

O artigo foi elaborado e revisado em conjunto por MCS Minayo e FG Cavalcante. O projeto foi coordenado e analisado por MCS Minayo, os dados coletados, organizados e analisados por FG Cavalcante e RMN Mangas. A revisão bibliográfica e a organização do campo foram feitas com apoio de JRA Souza. 


\section{Referências}

1. Shneidman ES. The psychological autopsy. Suicide Life-Threat Behav 1981; (11):325-340.

2. Shneidman ES. Autopsy of a Suicidal Mind. [S.1.]. Oxford: Oxford University Press; 2004.

3. Minayo MCS, Cavalcante FG, Souza ER. Methodological proposal for studying suicide as a complex phenomenon. Cad Saude Publica 2006; 22(8):15871596.

4. Cavalcante FG, Minayo MCS. Organizadores psíquicos e suicídio: retratos de uma autópsia psicossocial. In: Almeida-Prado MCC, organizador. $\mathrm{O}$ mosaico da violência. São Paulo: Vetor; 2004. p.371-343.

5. Minois G. História do suicídio. Lisboa: Editora Martins Fontes; 1994.

6. Shneidman ES. Comprehending Suicide: Landmarks in $20^{\text {th }}$ Century Suicidology. Washington DC: American Psychological Association; 2001.

7. Baechler J. Les Suicides. Paris: Calman-Lévy; 1975.

8. Organização Mundial de Saúde (OMS). Relatório Mundial sobre Violência e Saúde. Brasília: OMS, OPAS; 2002.

9. World Health Organization (WHO). Suicide; huge but preventable public health problem. Geneva: WHO; 2004.

10. Mitty E , Flores S. Suicide em Late Life. Geriatric Nursing 2008; 29(3):160-165.

11. Centers for Disease Control and Prevention. Webbased injury statistics query and reporting system. [site na Internet]. [acessado 2007 out 15]. Disponível: http://www.cdc.gov/ncipc/WISQARS/.

12. Conwell Y, Thompson C. Suicidal Behavior in Elders. Psychiatr Clin North Am 2008; 31(2):333-356.

13. Minayo MCS. Violência auto-infligida. In: Souza $\mathrm{ER}$, Minayo MCS, organizadoras. Impacto da violência na saúde dos brasileiros. Brasília: MS, OPAS; 2005. p. 205-239.

14. Shah AK. The relationship between suicide rates and age: an analysis of multinational data from the world Health Organization. Int Psychogeriatr 2007; (19):1141-1152.

15. Minayo MCS, Cavalcante FG, Mangas RM, JRA Souza. Motivos associados ao suicídio de pessoas idosas em autópsias psicológicas. Revista Trivium 2011; 3(1):109-117.

16. Minayo MCS, Cavalcante FG. Suicide in elderly people: a literature review. Rev Saude Publica 2010; 44(4):750-757.

17. Bertaux D. Biography and Society. The Life History Approach in the Social Sciences. Thousand Oaks: Sage Publications; 1981.

18. Durkheim E. O Suicídio: Um Estudo Sociológico. Rio de Janeiro: Zahar Editores; 1982.
19. Shah J, Bhat R. The relationship between elderly suicide rates and mental health funding, service provision and national policy: a cross-national study. Int Psychogeriatr 2008; 20(3):605-615.

20. Beeston D. Older People and Suicide. Centre for Ageing and Mental Health. Staffordshire: Staffordshire University; 2006.

21. Instituto de Criminalística Carlos Éboli (ICCE). Arquivos de mortes por violência no Rio de Janeiro. Rio de Janeiro: ICCE; 2009.

22. Evans-Pritchard EE. Os Nuer. São Paulo: Perspectiva; 1978.

23. Duberstein PR, Conwell Y, Conner KR, Eberly S, Caine ED. Suicide at 50 years of age and older: perceived physical illness, family discord and financial strain. Psychol Med 2004; 34(1):137-146.

24. Minayo MCS. Suicídio de pessoas idosas e fatores associados a esse fenômeno no Brasil e no mundo. In: Berzins MV, Malagutti W, organizadores. Rompendo o silêncio: faces da violência na velhice. São Paulo: Martinari; 2009. p.199-218.

25. Instituto Brasileiro de Geografia e Estatística (IBGE). Síntese dos indicadores sociais de 2004. Rio de Janeiro: IBGE; 2005.

26. Food and Drug Administration. US Departamento of Health \& Human Services. [site na Internet] 2010. [acessado 2010 ago 12]. Disponível em: http:// www.fda.gov/

27. De Leo D, Padoani W, Scocco P, Bille-Grahe U, Arcsnman E, Bjerke T, Crepet P, Haring C, Hawton K, Longvist J, Michel K, Pommeraud X, Querejeta I, Phillipe J, Salander-Renberg E, Schmidtke A, Weinacker B, Temesvary B, Wasserman D, SampaioFaria JG. Elderly suicidal behaviour: results from WHO/EURO Multicentre Study on Parasuicide. Int J Geriatr Psychiatr 2001; 16(3):300-310.

28. Organização Mundial da Saúde (OMS). Prevenção do suicídio: um manual para médicos clínicos gerais. OMS: Genebra; 2000.

29. Brasil. Ministério da Saúde (MS). Prevenção do Suicídio: manual dirigido a profissionais das equipes de saúde mental. Brasília: MS, OPAS, Unicamp; 2006. [acessado 2010 set 25]. Disponível em: http:/ /portal.saude.gov.br/portal/arquivos/pdf/manual_ prevencao_suicidio_saude_mental.pdf

Artigo apresentado em 13/04/2011

Aprovado em 10/06/2011

Versão final apresentada em 08/07/2011 
